\title{
The effect of Aloe ferox Mill. in the treatment of loperamide-induced constipation in Wistar rats
}

\author{
Olubunmi A Wintola, Taofik O Sunmonu, Anthony J Afolayan*
}

\begin{abstract}
Background: Constipation is the most common gastrointestinal complaint all over the world and it is a risk factor of colorectal cancer. In this study, the efficacy of aqueous leaf extract of Aloe ferox Mill. was studied against loperamide-induced constipation in Wistar rats.

Methods: Constipation was induced by oral administration of loperamide ( $3 \mathrm{mg} / \mathrm{kg}$ body weight) while the control rats received normal saline. The constipated rats were treated with 50, 100 and $200 \mathrm{mg} / \mathrm{kg}$ body weight/ day of the extract for 7 days during which the feeding characteristics, body weight, fecal properties and gastrointestinal transit ratio were monitored.

Results: The extract improved intestinal motility, increased fecal volume and normalized body weight in the constipated rats, which are indications of laxative property of the herb with the $200 \mathrm{mg} / \mathrm{kg}$ body weight of the extract showing the best efficacy.

Conclusion: The effect of the extract compares favourably well with senokot, a standard laxative drug. These findings have therefore, lent scientific credence to the folkloric use of the herb as a laxative agent by the people of the Eastern Cape of South Africa.
\end{abstract}

\section{Background}

Constipation is a highly prevalent functional gastrointestinal disorder affecting $3-15 \%$ of the general population [1,2]. In South Africa, 29\% of the population, consisting of both black and white suffer from constipation especially in the elderly [3]. The menace has a substantial impact on morbidity and quality of life [4], which may be characterized by unexplained abdominal pain, discomfort and bloating in association with altered bowel habits [5].

The use of chemical drugs such as senna, correctol, exlax, senokot and gaviscon is very common as a means of treating constipation. Statistics have shown that $43 \%$ of whites and $76.6 \%$ of blacks in South Africa indulge in the use of laxatives, out of which $14.3 \%$ and $21.5 \%$ respectively use more than one laxative at a time for the treatment of constipation [3]. The use of these orthodox drugs is however, limited due to their high cost and undesirable side affects [6]. Consequently, majority of the affected persons in South Africa rely on herbal

\footnotetext{
*Correspondence: aafolayan@ufh.ac.za

Department of Botany, University of Fort Hare, Alice 5700, South Africa
}

preparations for the treatment of the menace. For instance, some plant extracts are known to exhibit antispasmodic effects by stimulating water absorption in the intestine [7]. Apart from being fast acting, cheap and readily available, the users of medicinal plants for the treatment of constipation also believe that they have some control in their choice of medication [8].

Aloe ferox Mill. belongs to the family Asphodelaceae. The plant is widely distributed in the Southern Cape, Eastern Cape, Southern parts of KwaZulu Natal, the Free State and Lesotho. It is an arborescent perennial shrub with a single stem of $2-3 \mathrm{~m}$ in height. The plant is crowned by a large rosette of numerous leaves which are glaucous and oval-lanceolate. It is one of the widely used medicinal plants in traditional medicine because of its healing properties against many ailments [9]. For example, extract from the plant has been reported to be effective in the treatment of tooth abscesses [10], sexually transmitted infections [11], wound healing [12], arthritis and rheumatism [13], conjunctivitis and eye ailment [14] and as insect repellant [15]. The herb is also used traditionally as laxative; however, there is little or no scientific report to substantiate this claim. The 
present study was therefore, designed to evaluate the laxative activity of the aqueous leaf extract of Aloe ferox on loperamide-induced constipated rats and the effect was compared with senokot, a standard laxative drug.

\section{Methods}

\section{Drugs and chemicals}

Loperamide hydrochloride, carmine and carboxymethylcellulose were procured from Sigma Chemical Co., St Louis, MO, USA while senokot was a product of Reckitt Benckiser Pharmaceutical (Pty) Ltd, South Africa. All other chemicals and reagents used were of analytical grade.

\section{Plant materials}

Fresh mature whole leaves of Aloe ferox were collected in Ntselamanzi Area of Nkonkobe Municipality in the Eastern Cape Province of South Africa. The Plant was authenticated by Prof DS Grierson; a botanist in the Department of Botany, University of Fort Hare and a voucher specimen (Wintola Med.2009/01) was prepared and deposited in the University herbarium.

\section{Preparation of aqueous extract}

The leaves of $A$. ferox were thoroughly washed with distilled water, cut into thin slices and dried in the oven at $50^{\circ} \mathrm{C}$ for $24 \mathrm{~h}$. The dried leaves were grinded into powder and $100 \mathrm{~g}$ of the material was extracted by shaking for $24 \mathrm{~h}$ in $1000 \mathrm{ml}$ of distilled water on an orbital shaker (SO1 orbital shaker, Stuart scientific, Stone U. K). The extract obtained was filtered through Whatman No $1(70 \mathrm{~mm})$ filter paper and Freeze dried (Vir Tis benchtop k, Vir Tis company Gardiner NY) to give a yield of $24.4 \mathrm{~g}$. This was reconstituted in distilled water to give the required doses of 50,100 and $200 \mathrm{mg} / \mathrm{kg}$ body weight for the experiment.

\section{Animal used}

Male albino rats (Rattus norvegicus) of Wistar strain with a mean weight of $140 \pm 3.67 \mathrm{~g}$ were obtained from the experimental animal house of the Agricultural and Rural Development Research Institute (ARDRI), University of Fort Hare, Alice. The animals were housed individually in clean metabolic cages placed in a well ventilated house with optimum condition (temperature $23 \pm 1^{\circ} \mathrm{C}$, photoperiod; $12 \mathrm{~h}$ natural light and $12 \mathrm{~h}$ dark; humidity; $45-50 \%)$. They were acclimatized to the animal house condition for 7 days during which they were allowed free access to commercial pelleted rat chow (Pioneer Food (Pty) Ltd, Huguenot, South Africa) and water. The cleaning of the cages was done on a daily basis. All animal treatments were in accordance with international ethical guidelines and the National Institute of Health guide concerning the care and use of laboratory animals. The study was carried out following the approval from the Ethical Committee of the University of Fort Hare on the use and care of animals.

\section{Induction of constipation in the rats}

Constipation was induced in the animals by oral administration of $1 \mathrm{ml}$ loperamide $(3 \mathrm{mg} / \mathrm{kg}$ body weight in $0.9 \%$ sodium chloride for 3 days) [16], while the control rats were administered with the normal saline only. The Passage of reduced, hard and dry fecal pellets indicated constipation in the rats.

\section{Experimental design}

The rats were grouped into six of four rats each. The animals in Group 1 (control) and Group 2 (constipated control) were administered with distilled water. Groups 3,4 and 5 comprised constipated rats given 50, 100 and $200 \mathrm{mg} / \mathrm{kg}$ body weight/day of $A$. ferox extract respectively while Group 6 were constipated rats administered with senokot. The administration was done using metal oropharyngeal cannula. The water intake, feed intake and body weight gain of all the rats were recorded during experimental period and treatment continued for 7 days.

\section{Total number, dry weight and water content of fecal pellet}

The excreted fecal pellets of individual rats were collected everyday at 09:00 $\mathrm{h}$ throughout the duration of the experiment. Total number, weight and water content of the pellets were determined. The water content was calculated as the difference between the wet and dry weights of the pellet.

\section{Gastrointestinal transit (GIT) ratio}

GIT ratio was measured according to the method of Nakagura et al. [17]. On the 7th day, $1 \mathrm{ml}$ of carmine (3 g suspended in $50 \mathrm{ml}$ of $0.5 \%$ carboxymethylcellulose) was orally administered to the rats. One hour after administering the marker, the animals were sacrificed and the small intestines were quickly removed. The distance over which the carmine had travelled and the total length of the small intestine were measured. The GIT ratio was expressed as the percentage of the distance travelled by the carmine relative to the total length of the small intestine.

\section{Statistical analysis}

Data were expressed as means \pm SD of four replicates and were subjected to one way analysis of variance (ANOVA) followed by Duncan multiple range test to determine significant differences in all the parameters. Values were considered statistically significant at $\mathrm{p}<0.05$. 
Table 1 Effect of loperamide on feed intake, water intake and fecal properties of constipated rats

\begin{tabular}{lcc}
\hline Parameters & Normal Control & Constipated rats \\
\hline Feed intake & $15.32 \pm 1.12$ & $17.05 \pm 0.74^{*}$ \\
Water intake & $19.00 \pm 1.41$ & $8.92 \pm 0.68^{* *}$ \\
Number of fecal pellet & $64.67 \pm 2.80$ & $24.04 \pm 0.94^{* *}$ \\
Water content of fecal pellet & $1.52 \pm 0.17$ & $0.57 \pm 0.10^{* *}$ \\
Weight of fecal pellet & $6.38 \pm 0.30$ & $2.95 \pm 0.09^{* *}$ \\
\hline
\end{tabular}

Data are mean \pm SD values $(n=4) ;{ }^{*}$ not significantly different; ${ }^{* *}$ significantly different from normal control at $\mathrm{P}<0.05$

\section{Results}

Loperamide significantly reduced the water intake, the number, water content and the weight of the fecal pellets (Table 1). This was an indication of the induction of constipation in the rats. However, there was no significant difference in feed intake between the control and the constipated animals.

While water consumption decreased in the untreated constipated rats, the administration of aqueous extract of $A$. ferox significantly increased the water intake in constipated rats (Table 2). Again, there was no significant difference in the feed intake of all the animals. Similarly, the extract significantly increased the number, water content and weight of fecal pellets in the constipated rats in a dosage-dependent manner. The body weights of the constipated animals were also normalized following the treatment with the extract.

Loperamide administration significantly reduced gastrointestinal motility in the untreated constipated rats (Fig.1). The treatment with the extract, however, increased the gastrointestinal movement in a dose dependent manner which compared favourably well with senokot, a standard constipation drug.

\section{Discussion}

The use of herbal remedies in the treatment of constipation is a common practice in many countries of the world including South Africa [13,18]. The present study has clearly demonstrated that aqueous extract of Aloe ferox has laxative activity; which is comparable to senokot, a standard laxative drug.
The use of loperamide as constipation inducer is well documented. The drug inhibits intestinal water secretion [19] and colonic peristalsis [20]. This inhibition extends fecal evacuation time and delays intestinal luminal transit [21]. Loperamide-induced constipation is therefore considered to be a model of spastic constipation [22].

The observed reduction in the number, weight and water content of fecal pellets following the treatment with the drug indicated induction of constipation in the rats. Similar observation was reported by Shimotoyodome et al. [23]. The reduction in the water consumed by the constipated animals may also be due to the effect of the drug which probably accounted for the reduction in water content of the fecal pellets. However, the drug did not prevent the animals from feeding adequately.

The administration of aqueous extract of $A$. ferox to the constipated rats was effective in influencing increased defecation frequency, fecal volume and motility of the colon. These are indications of the laxative property of the plant extract. This may be due to the presence of anthranoid glycosides derivatives of which aloin is the main compound [24,25]. According to Izzo et al. [26], aloin is metabolized by the colonic flora to reactive aloe-emodin which is responsible for the purgative activity. This compound possibly exerts its action by disturbing the equilibrium between the absorption of water from the intestinal lumen via an active sodium transport [27] and the secretion of water into the lumen by prostaglandin-dependent mechanism [28,29].

Although the feed intake did not differ among the groups, the gain in body weight was higher in the untreated constipated rats compared to the extract treated groups. This may be due to the accumulation of fecal pellets in their bodies, thus accounting for the extra weight. This clearly indicates that the plant extract increased intestinal secretion and motility in the constipated rats. Similar observation was reported by Niwa et al. [30] where dietary fiber was used for the treatment of morphineinduced constipation in rats. Of particular interest is the fact that the effect of the extract of $A$. ferox was dose dependent in this study. The effect of the highest dosage actually compared favourably well with senokot.

Table 2 Effect of aqueous extract of Aloe ferox on feed and water intake, body weight gain and fecal properties of constipated rats

\begin{tabular}{|c|c|c|c|c|c|c|}
\hline \multirow[t]{2}{*}{ Parameters } & \multirow[t]{2}{*}{ Normal control } & \multirow[t]{2}{*}{ Constipated control } & \multicolumn{3}{|c|}{ Constipated $+A$. ferox (mg/kg body weight) } & \multirow[t]{2}{*}{ Senokot } \\
\hline & & & 50 & 100 & 200 & \\
\hline Feed intake & $17.18 \pm 1.36^{\mathrm{a}}$ & $19.23 \pm 3.86^{\mathrm{a}}$ & $19.90 \pm 1.61^{\mathrm{a}}$ & $20.54 \pm 1.38^{\mathrm{a}}$ & $17.80 \pm 1.60^{\mathrm{a}}$ & $19.97 \pm 3.31^{\mathrm{a}}$ \\
\hline Water intake & $19.62 \pm 2.22^{\mathrm{a}}$ & $11.72 \pm 2.47^{b}$ & $16.57 \pm 2.05^{\mathrm{a}}$ & $17.24 \pm 0.17^{\mathrm{a}}$ & $19.79 \pm 2.33^{\mathrm{a}}$ & $18.14 \pm 0.61^{a}$ \\
\hline Number of fecal Pellet & $73.57 \pm 4.39^{a}$ & $38.20 \pm 2.21^{b}$ & $45.43 \pm 1.90^{c}$ & $57.57 \pm 1.62^{d}$ & $69.83 \pm 4.49^{a}$ & $63.00 \pm 3.11^{\mathrm{a}}$ \\
\hline Water content of fecal pellet (ml) & $1.40 \pm 0.08^{\mathrm{a}}$ & $1.04 \pm 0.09^{b}$ & $1.75 \pm 0.21^{c}$ & $1.95 \pm 0.11^{c}$ & $2.25 \pm 0.21^{d}$ & $2.09 \pm 0.06^{\mathrm{d}}$ \\
\hline Weight of fecal pellet (g) & $7.14 \pm 0.23^{\mathrm{a}}$ & $3.34 \pm 0.38^{b}$ & $5.72 \pm 0.18^{c}$ & $7.42 \pm 0.33^{\mathrm{a}}$ & $8.10 \pm 0.72^{\mathrm{a}}$ & $7.31 \pm 0.25^{\mathrm{a}}$ \\
\hline Body weight gain (g) & $15.30 \pm 1.00^{\mathrm{a}}$ & $33.80 \pm 1.00^{b}$ & $14.20 \pm 0.71^{\mathrm{a}}$ & $13.20 \pm 2.16^{\mathrm{a}}$ & $12.50 \pm 1.85^{\mathrm{a}}$ & $15.35 \pm 1.21^{\mathrm{a}}$ \\
\hline
\end{tabular}

Data are mean \pm SD values $(n=4)$. Row values with different superscripts from the control are significantly different $(P<0.05)$ 


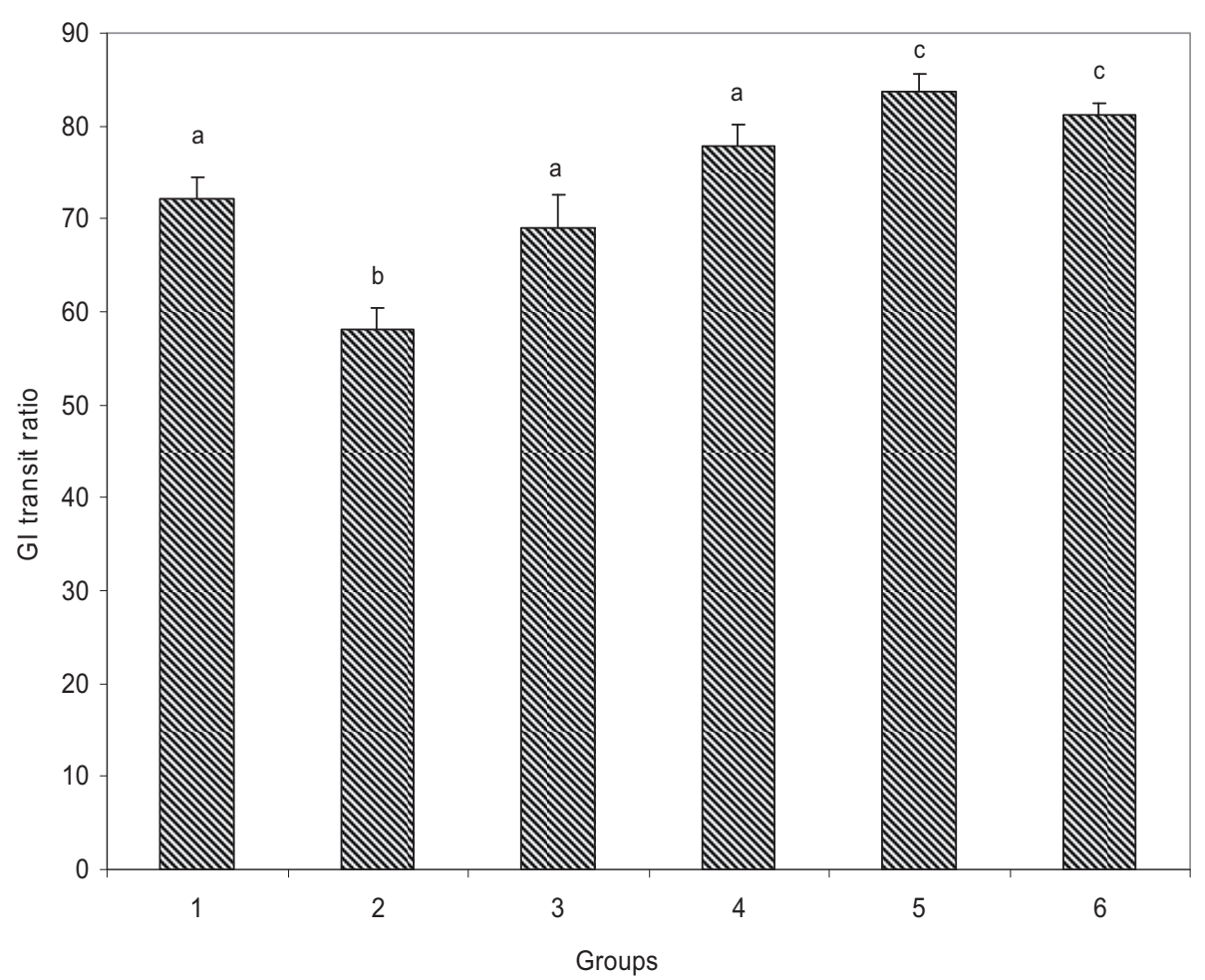

Figure 1 Effect of aqueous extract of Aloe ferox on gastrointestinal transit ratio in loperamide-induced constipated rats. Data are means of four determinations \pm SD. Bars with different letters from the control are significantly different $(P<0.05)$.

The transit process of the entire gastrointestinal tract reflected the overall gastrointestinal motor activity. Measuring colonic transit time is useful in constipation, abdominal bloating and refractory irritable bowel syndrome. It also provides quantitative information about colonic transit, enables the identification and characterization of transit abnormalities and allows assessment of the severity of the problem as well as the response to therapy [31]. In this study, carmine was used as the marker used to measure the colonic movement. The extract increased intestinal motility which, in turn, enhanced colonic peristalsis in the rats. The possible mechanism of the extract in this process may be by enhancing the release of fluid thereby increasing intestinal secretion. The laxative effect of the extract could also be attributed to changes in the intestinal motility, which produced an increase in intestinal transit and colonic movement [32]. Generally, the effect of the treatment with the extract compared favourably well to that of senokot. This is an indication that the herb was effective in ameliorating bowel obstruction, thereby enhancing easy movement in the intestine.

\section{Conclusion}

The present study revealed that oral administration of aqueous extract of Aloe ferox exhibited laxative activity in loperamide induced constipated rats. This suggests the beneficial effects of the herb in improving intestinal motility. It is, however, very important to note that the extract at 100 and $200 \mathrm{mg} / \mathrm{kg}$ body weight showed better laxative action than at $50 \mathrm{mg} / \mathrm{kg}$ body weight. The effect of the extract compared favourably with senokot. These findings have lent scientific support to the folkloric use of $A$. ferox as a laxative agent.

\section{Acknowledgements}

This research was supported by grants from Govan Mbeki Research and Development Centre, University of Fort Hare, South Africa.

\section{Authors' contributions}

OA participated in the design of the study, prepared the aqueous extract and carried out the study involving fecal pellets and gastrointestinal transit ratio. TO conceived of the study, participated in its design and performed the statistical analysis. AJ participated in the design of the study and coordination and helped to revise the manuscript. All authors read and approved the final manuscript.

\section{Competing interests}

The authors declare that they have no competing interests.

Received: 26 December 2009 Accepted: 19 August 2010 Published: 19 August 2010

\section{References}

1. Jones R, Lydeard S: Irritable bowel syndrome in the general population. BMJ 1992, 304:87-90.

2. Talley NJ, Stanghellini V, Heading RC, Koch KL, Malagelada JR, Tytgat GNJ: Functional gastroduodenal disorders. Gut 1999, 45(suppl 2):1137-1142. 
3. Meiring PJ, Joubert G: Constipation in elderly patients attending a polyclinic. S Afr Med J 1985, 88:888-890.

4. Drossman DA, Li Z, Andruzzi E, Temple RD, Talley NJ, Thompson WG, Whitehead WE, Janssens US: House-holder survey of functional gastrointestinal disorders: Prevalence, sociodemography and health impact. Dig Dis Sci 1993, 38:1569-1580.

5. Thompson WG, Longstreth GF, Drossman DA, Heaton KW, Irvine EJ, MullerLissner SA: Functional bowel disorders and functional abdominal pain. Gut 1999, 45(Suppl 2):1143-1147.

6. Erasto P, Adebola PO, Grierison DS, Afolayan AJ: An ethnobotanical study of plants used for the treatment of diabetes in Eastern Cape Province, South Africa. Afr J Biotech 2005, 4:1458-1460.

7. Palombo EA: Phytochemicals from traditional medicinal plants used in the treatment of Diarrhea: Mode of action and effects on intestinal function. Phytother Res 2006, 20:717-724.

8. Joshi BS, Kaul PN: Alternative medicine: herbal drugs and their critical appraisal-Part I Program. Drug Res 2001, 56:1-76.

9. Zahn M, Trinh T, Jeong ML, Wang D, Abeysingbe P, Jia Q: A revised-phase high performance liquid chromatographic method for the determination of Aloesin A and Anthraquinone of Aloe ferox. Physicochem Analy 2007. 19:122-126.

10. Githens TS: Drug plants of Africa Pennsylvania: Philadelphia: University of Pennsylvania Press 1979.

11. Kambizi L, Goosen BM, Taylor MB, Afolayan AJ: Anti-viral effects of aqueous extracts of Aloe ferox and Withania somnifera on herpes simplex virus type 1 in cell culture. S Afr J Sci 2007, 103:359-360.

12. Grierson DS, Afolayan AJ: An ethnobotanical study of plants used for the treatment of wounds in the Eastern Cape, South Africa. $J$ Ethnopharmacol 1999, 67:327-332

13. Van Wyk B-E, Van Oudtshoorn B, Gericke N: Medicinal plants of South Africa Pretoria, South Africa, Briza Publication 1997.

14. Crouch NR, Symmonds R, Spring A, Diederichs N: Fact sheet for growing popular medicinal plant species. Commercializing Medicinal plants: A Southern African Guide Stellenbosch Sun PressDiederichs N 2006, 100-102.

15. Watt J, Breyer-Brandwijk MG: Medicinal and poisonous plants of southern and Eastern Africa London, Livingstone, 21962

16. Bustos D, Ogawa K, Pons S, Soriano E, Banji JC, Bustos FL: Effect of loperamide and bisacodyl on intestinal transit time, fecal weight and short chain fatty acid excretion in the rat. Acta Gastroenterol Latinoam 1991, 21:3-9.

17. Nagakura Y, Naitoh Y, Kamato T, Yamano M, Miyata K: Compounds processing $5-\mathrm{HT}_{3}$ receptor antagonistic activity inhibit intestinal propulsion in mice. Eur J Pharmacol 1996, 311:67-72

18. Kim HS: Do not put too much value on conventional medicines. $J$ Ethnopharmacol 2005, 100:37-39.

19. Hughes $\mathrm{S}$, Higgs NB, Turnberg LA: Loperamide has antisecretory activity in the human jejunum in vivo. Gut 1984, 25:931-935.

20. Sohji Y, Kawashima K, Shimizu M: Pharmacological studies of loperamide, an anti-diarrheal agent. Folia Pharmacol Jpn 1978, 74:155-163.

21. Yamada K, Onoda Y: Comparison of the effects of T-1815, yohimbine and naloxone on mouse colonic propulsion. J Smooth Muscle Res 1993, 29:47-53.

22. Takasaki K, Kishibayashi N, Ishii A, Karasawa A: Effects of KW-5092, a novel gastroprokinetic agent, on the delayed colonic propulsion in rats. Jpn J Pharmacol 1994, 65:67-71.

23. Shimotoyodome A, Meguro S, Hase T, Tokimitsu I, Satake T: Decreased colonic mucus in rats with loperamide-induced constipation. Comp Biochem Physiol 2000, 126:203-211.

24. Ishii Y, Tanizawa H, Takino Y: Studies of aloe: V. Mechanism of cathartic effect. Biol Pharm Bull 1994, 17(5):651-653.

25. Blumenthal M, Busse WR, Goldberg A, Hall T: German Commission E Monographs America Botanical Council and Integrative Medicine communication, Boston, Integrative Medicine Publishers 1998

26. Izzo AA, Sautebin L, Borrelli F, Longo R, Capasso F: The role of nitric oxide in aloe-induced diarrhoea in rat. Eur J Pharmacol 1999, 368:43-48.

27. Ishii Y, Tanizawa H, Takino Y: Studies of aloe: III. Mechanism of cathartic effect. Chem Pharm Bull 1990, 38:197-200.

28. Collier HOJ, Mcdonald-Gibson WJ, Sated SA: Stimulation of prostaglandin biosynthesis by drugs: effects in vitro of some drugs affecting gut function. Br J Pharmacol 1976, 58:193-198.
29. Capasso F, Mascolo N, Autore G, Duraccio MR: Effect of indomethacin on aloin and 1,8 dioxianthraquinone-induced production of prostaglandins in rat isolated colon. Prostaglandins 1983, 26:557-562.

30. Niwa T, Nakao M, Hoshi S, Yamada K, Inagaki K, Nishida M, Nabeshima T: Effect of Dietary Fiber on Morphine-induced constipation in Rats. Biosc Biotechnol Biochem 2002, 66(6):1233-1240.

31. Degan L: Gastrointestinal motility-physiology and methods of measurement. Ther Umsch 2007, 64(4):195-199.

32. Capasso F, Gaginella TS: Laxatives, a Practical Guide Milan Springer Italia 1997.

\section{Pre-publication history}

The pre-publication history for this paper can be accessed here: http://www.biomedcentral.com/1471-230X/10/95/prepub

doi:10.1186/1471-230X-10-95

Cite this article as: Wintola et al: The effect of Aloe ferox Mill. in the treatment of loperamide-induced constipation in Wistar rats. BMC Gastroenterology 2010 10:95.

\section{Submit your next manuscript to BioMed Central and take full advantage of:}

- Convenient online submission

- Thorough peer review

- No space constraints or color figure charges

- Immediate publication on acceptance

- Inclusion in PubMed, CAS, Scopus and Google Scholar

- Research which is freely available for redistribution
C) Biomed Central 